\title{
Are patients with high-risk polycythemia vera receiving cytoreductive medications? A retrospective analysis of real-world data
}

\author{
Dilan Paranagama ${ }^{1 *}$, Philomena Colucci ${ }^{1}$, Kristin A. Evans ${ }^{2}$, Machaon Bonafede $^{2}$ and Shreekant Parasuraman ${ }^{1}$
}

\begin{abstract}
Background: Patients with polycythemia vera (PV) have a higher mortality risk compared with the general population, primarily driven by cardiovascular disease, thrombotic events (TEs), and hematologic transformations. The goal of risk-adapted therapy in PV is prevention of TEs. Current treatment recommendations indicate that high-risk patients (aged $\geq 60$ years and/or with history of TEs) should be managed with cytoreductive medications, phlebotomy, and low-dose aspirin. This noninterventional study was conducted to describe real-world cytoreductive medication treatment in adult patients with PV, stratified by risk, in the United States.

Methods: This retrospective analysis used claims data from the Truven Health MarketScan ${ }^{\circledR}$ database. Inclusion criteria were $\geq 2$ nondiagnostic claims for $\mathrm{PV} \geq 30$ days apart, age $\geq 18$ years, continuous enrollment during the preindex period (January 1 to December 31, 2012), and continuous enrollment or death during the postindex period (January 1 , 2013, to December 31, 2014). Assessments included patient demographics, clinical characteristics, and treatment with cytoreductive medications.

Results: A total of 2856 patients were identified for this analysis, including 1823 with high-risk PV and 1033 with lowrisk PV. Mean (SD) age was 62.5 (13.5) years, and 65.9\% of patients were male. Preindex comorbid conditions of interest were more common in high-risk than low-risk patients, including hypertension (65.0\% vs 43.1\%), type 2 diabetes ( $21.7 \%$ vs $10.1 \%)$, and congestive heart failure (6.6\% vs $0.6 \%)$. Among patients who received preindex cytoreductive therapy, the most commonly used medications in high-risk $(n=666)$ and low-risk $(n=160)$ patients were hydroxyurea (94.7 and 87.5\%, respectively), anagrelide (7.4 and 11.9\%), and interferon (1.7 and $4.4 \%)$. Among patients who initiated cytoreductive therapy postindex, the most commonly used medications in high-risk $(n=100)$ and low-risk $(n=35)$ patients were hydroxyurea (97.0 and $91.4 \%$, respectively), anagrelide (4.0 and 2.9\%), and interferon (2.0 and 8.6\%). Overall, $42.0 \%$ of high-risk and $18.9 \%$ of low-risk patients received cytoreductive medication during the preindex or postindex periods.
\end{abstract}

Conclusions: Despite consistent guideline recommendations for cytoreductive therapy in patients with high-risk PV, this analysis revealed that only a minority of these patients received cytoreductive medication. A notable proportion of high-risk patients with PV would likely benefit from a revised treatment plan that aligns with current guidelines.

Keywords: Anagrelide, Hydroxyurea, Interferons, Myeloproliferative disorders, Polycythemia vera

\footnotetext{
*Correspondence: dparanagama@incyte.com

${ }^{1}$ Incyte Corporation, 1801 Augustine Cut-Off, Wilmington, DE 19803, USA

Full list of author information is available at the end of the article
} 


\section{Background}

The Philadelphia chromosome-negative myeloproliferative neoplasms (MPNs), including polycythemia vera (PV), essential thrombocythemia, and myelofibrosis, are a group of clonal hematologic malignancies with overlapping pathology and clinical features [1]. PV is primarily characterized by erythrocytosis and constitutively active mutations in Janus kinase 2 [2]. Patients with PV commonly report chronic symptoms, including fatigue, abdominal discomfort, night sweats, concentration problems, bone pain, early satiety, and inactivity, which have a notable influence on quality of life [3]. In the recent MPN Landmark survey, the majority of patients with PV reported that their disease interfered with family or social life and that pain/discomfort associated with their disease interfered with daily activities [3].

Patients with PV also have a higher mortality risk compared with the general population [4], primarily driven by cardiovascular disease, thrombotic events (TEs), and hematologic transformations [5]. The goal of risk-adapted therapy for patients with PV is the prevention of TEs. Treatment recommendations from the European LeukemiaNet (ELN) [6] and the National Comprehensive Cancer Network (NCCN) [7] indicate that patients with low-risk PV be managed with aspirin and phlebotomy. However, patients with high-risk PV (age $\geq 60$ years and/or with a history of TEs) should be managed with cytoreductive medication in addition to phlebotomy and low-dose aspirin (Fig. 1 [6-8]). Furthermore, cytoreductive medications are recommended for patients with PV exhibiting symptomatic thrombocytosis or progressive leukocytosis, regardless of risk status [6, 7].

In the present analysis, cytoreductive medication use was evaluated in patients with PV stratified by high vs low risk to determine the extent to which real-world management aligns with guideline recommendations. This is the first study to examine real-world cytoreductive treatment practices in patients with PV relative to published treatment guidelines.

\section{Methods \\ Patients and study design}

This was a noninterventional, retrospective cohort analysis of claims from the Truven Health MarketScan ${ }^{\circledR}$ database. Eligible patients lived in the United States and were $\geq 18$ years of age with $\geq 2$ nondiagnostic claims for PV (International Classification of Diseases, Ninth Edition, Clinical Modification code 238.4) $\geq 30$ days apart. The index date was January 1, 2013, approximately 2 years after the ELN treatment recommendations for PV [6] were published. Patients had continuous enrollment during the preindex period (January 1 to December 31, 2012) and continuous enrollment or death during the postindex period (January 1, 2013, to December 31, 2014). Patients with claims for myelodysplastic syndrome, myelofibrosis, acute myelogenous leukemia, or secondary polycythemia were excluded.

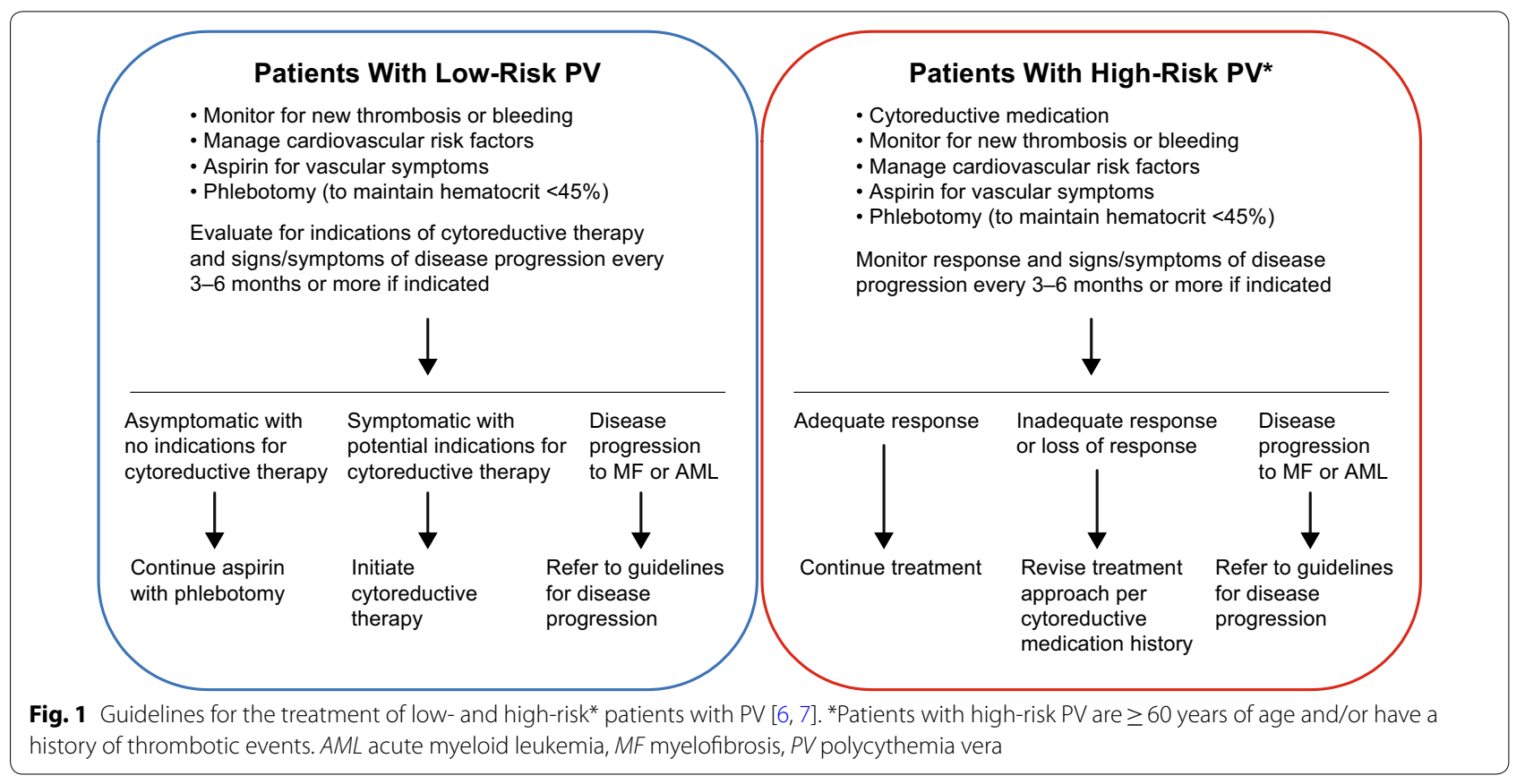




\section{Assessments}

Patients were stratified based on PV risk status at index, and patient demographics were assessed at the index date. Clinical characteristics, comorbidities, and concomitant medications were assessed during the preindex period. Cytoreductive medication use and phlebotomy procedures were assessed during the entire study period (i.e., preindex and postindex periods). All data were analyzed using descriptive statistics.

\section{Results}

\section{Disposition and demographics}

A total of 2856 patients were identified, of whom 1033 had low-risk PV and 1823 had high-risk PV. The mean age of all patients was 62.5 years and the majority were men (Table 1). Among high-risk patients, $62.8 \%$ were $\geq 60$ years of age with no history of TEs, $9.1 \%$ had a history of TEs and were $<60$ years of age, and $28.1 \%$ were $\geq 60$ years of age and had a history of TEs.

\section{Clinical characteristics}

Out of 12 comorbid conditions, 10 were more common in high- vs low-risk patients (Table 2). Treatment with cardiovascular medication was more common in high- vs low-risk patients, whereas percentages of patients treated with corticosteroids, antidepressants, and nonsteroidal anti-inflammatory drugs were generally similar between the risk groups (Table 2).

\section{Cytoreductive medication usage}

During the preindex period, $36.5 \%(666 / 1823)$ of patients with high-risk PV and 15.5\% (160/1033) of patients with low-risk PV received cytoreductive therapy. The most common preindex cytoreductive therapies in high- and low-risk patients were hydroxyurea (94.7 and 87.5\%, respectively), anagrelide (7.4 and $11.9 \%)$, and interferon (1.7 and 4.4\%; Fig. 2a).

Among patients who did not receive cytoreductive medication during the preindex period, 6.7\% (135/2030) initiated a cytoreductive therapy during the postindex period; $74.1 \%(100 / 135)$ of whom were high risk and $25.9 \%(35 / 135)$ of whom were low risk. The most common postindex cytoreductive therapies in high- and low-risk patients were hydroxyurea (97.0 and 91.4\%, respectively), anagrelide (4.0 and $2.9 \%$ ), and interferon (2.0 and 8.6\%; Fig. 2b).

Overall, $42.0 \%(766 / 1823)$ of patients with high-risk PV and 18.9\% (195/1033) of patients with low-risk PV received cytoreductive medications during either the preindex or postindex periods (Fig. 3).
Table 1 Demographics

\begin{tabular}{|c|c|c|c|}
\hline & $\begin{array}{l}\text { Low-risk PV } \\
(n=1033)\end{array}$ & $\begin{array}{l}\text { High-risk PV } \\
(n=1823)\end{array}$ & $\begin{array}{l}\text { All patients } \\
(\mathrm{N}=2856)\end{array}$ \\
\hline Mean (SD) age, years & $49.7(8.6)$ & $69.7(9.9)$ & $62.5(13.5)$ \\
\hline \multicolumn{4}{|l|}{ Age group, $n(\%)$, years } \\
\hline $18-34$ & $73(7.1)$ & $5(0.3)$ & $78(2.7)$ \\
\hline $35-54$ & $573(55.5)$ & $86(4.7)$ & $659(23.1)$ \\
\hline $55-64$ & $387(37.5)$ & $522(28.6)$ & $909(31.8)$ \\
\hline$\geq 65$ & $\mathrm{NA}$ & $1210(66.4)$ & $1210(42.4)$ \\
\hline \multicolumn{4}{|l|}{ Sex, n (\%) } \\
\hline Male & $757(73.3)$ & $1125(61.7)$ & $1882(65.9)$ \\
\hline Female & $276(26.7)$ & $698(38.3)$ & $974(34.1)$ \\
\hline \multicolumn{4}{|c|}{ Geographic region, n (\%) } \\
\hline South & $402(38.9)$ & $558(30.6)$ & $960(33.6)$ \\
\hline North Central & $230(22.3)$ & $499(27.4)$ & $729(25.5)$ \\
\hline Northeast & $218(21.1)$ & $482(26.4)$ & $700(24.5)$ \\
\hline West & $169(16.4)$ & $270(14.8)$ & $439(15.4)$ \\
\hline Unknown & $14(1.4)$ & $14(0.8)$ & $28(1.0)$ \\
\hline \multicolumn{4}{|l|}{ Insurance payer, n (\%) } \\
\hline Commercial & $1033(100)$ & $613(33.6)$ & $1646(57.6)$ \\
\hline Medicare & 0 & $1210(66.4)$ & $1210(42.4)$ \\
\hline \multicolumn{4}{|c|}{ Insurance plan type, n (\%) } \\
\hline $\mathrm{PPO}$ & $669(64.8)$ & $943(51.7)$ & $1612(56.4)$ \\
\hline Comprehensive & $47(4.5)$ & $576(31.6)$ & $623(21.8)$ \\
\hline $\mathrm{HMO}$ & $106(10.3)$ & $150(8.2)$ & $256(9.0)$ \\
\hline POS & $83(8.0)$ & $70(3.8)$ & $153(5.4)$ \\
\hline $\mathrm{CDHP}$ & $72(7.0)$ & $37(2.0)$ & $109(3.8)$ \\
\hline HDHP & $32(3.1)$ & $13(0.7)$ & $45(1.6)$ \\
\hline $\mathrm{EPO}$ & $6(0.6)$ & $18(1.0)$ & $24(0.8)$ \\
\hline POS with capitation & $7(0.7)$ & $2(0.1)$ & $9(0.3)$ \\
\hline Unknown & $11(1.1)$ & $14(0.8)$ & $25(0.9)$ \\
\hline
\end{tabular}

Data assessed on the index date (January 1, 2013)

$C D H P$ consumer-driven health plan, EPO exclusive provider organization, $H D H P$ high-deductible health plan, $H M O$ health maintenance organization, $N A$ not applicable, $P O S$ point of service, $P P O$ preferred provider organization, $P V$ polycythemia vera, $S D$ standard deviation

\section{Phlebotomy procedures}

A larger proportion of patients who did not receive cytoreductive therapies had phlebotomies during the preindex period compared with those who had preindex cytoreductive therapy [43.3\% (880/2030) vs 37.3\% (308/826), respectively]. The trend was similar in patients with high-risk PV [41.7\% (483/1157) vs 36.8\% (245/666)] and patients with low-risk PV [45.5\% (397/873) vs 39.4\% (63/160)].

\section{Discussion}

This analysis was designed to assess real-world cytoreductive medication treatment practices in patients with PV per the ELN recommendations published in 2011 [6]. Despite current recommendations indicating that patients 
Table 2 Clinical characteristics

\begin{tabular}{|c|c|c|c|}
\hline & Low-risk PV ( $n=1033)$ & High-risk PV $(n=1823)$ & All patients $(\mathrm{N}=2856)$ \\
\hline \multicolumn{4}{|l|}{ Comorbid condition, n (\%) } \\
\hline Hypertension & $445(43.1)$ & $1185(65.0)$ & $1630(57.1)$ \\
\hline Chronic pain & $187(18.1)$ & $473(25.9)$ & $660(23.1)$ \\
\hline Diabetes (type 2) & $104(10.1)$ & $396(21.7)$ & $500(17.5)$ \\
\hline Osteoarthritis & $102(9.9)$ & $366(20.1)$ & $468(16.4)$ \\
\hline Cancer (excluding leukemia and MM) & $66(6.4)$ & $381(20.9)$ & $447(15.7)$ \\
\hline Gastroesophageal reflux disease & $121(11.7)$ & $224(12.3)$ & $345(12.1)$ \\
\hline Anemia & $64(6.2)$ & $168(9.2)$ & $232(8.1)$ \\
\hline Depression & $81(7.8)$ & $123(6.7)$ & $204(7.1)$ \\
\hline Anxiety & $73(7.1)$ & $117(6.4)$ & $190(6.7)$ \\
\hline Congestive heart failure & $6(0.6)$ & $121(6.6)$ & $127(4.4)$ \\
\hline Non-AML leukemia & $5(0.5)$ & $14(0.8)$ & $19(0.7)$ \\
\hline $\mathrm{MM}$ & $1(0.1)$ & $8(0.4)$ & $9(0.3)$ \\
\hline \multicolumn{4}{|l|}{ Concomitant medication, n (\%) } \\
\hline Cardiovascular ${ }^{\mathrm{a}}$ & $636(61.6)$ & $1526(83.7)$ & $2162(75.7)$ \\
\hline Corticosteroid (oral or IV) & $306(29.6)$ & $510(28.0)$ & $816(28.6)$ \\
\hline Antidepressant & $228(22.1)$ & $369(20.2)$ & $597(20.9)$ \\
\hline NSAID & 205 (19.8) & $314(17.2)$ & $519(18.2)$ \\
\hline
\end{tabular}

Clinical characteristics evaluated during the preindex period (January 1 to December 31, 2012)

$A M L$ acute myeloid leukemia, IV intravenous, MM multiple myeloma, NSAID nonsteroidal anti-inflammatory drug, $P V$ polycythemia vera

a Includes antihypertensives, statins, antidiabetic medications, anticoagulants, antiplatelet medications, and other lipid-lowering medications

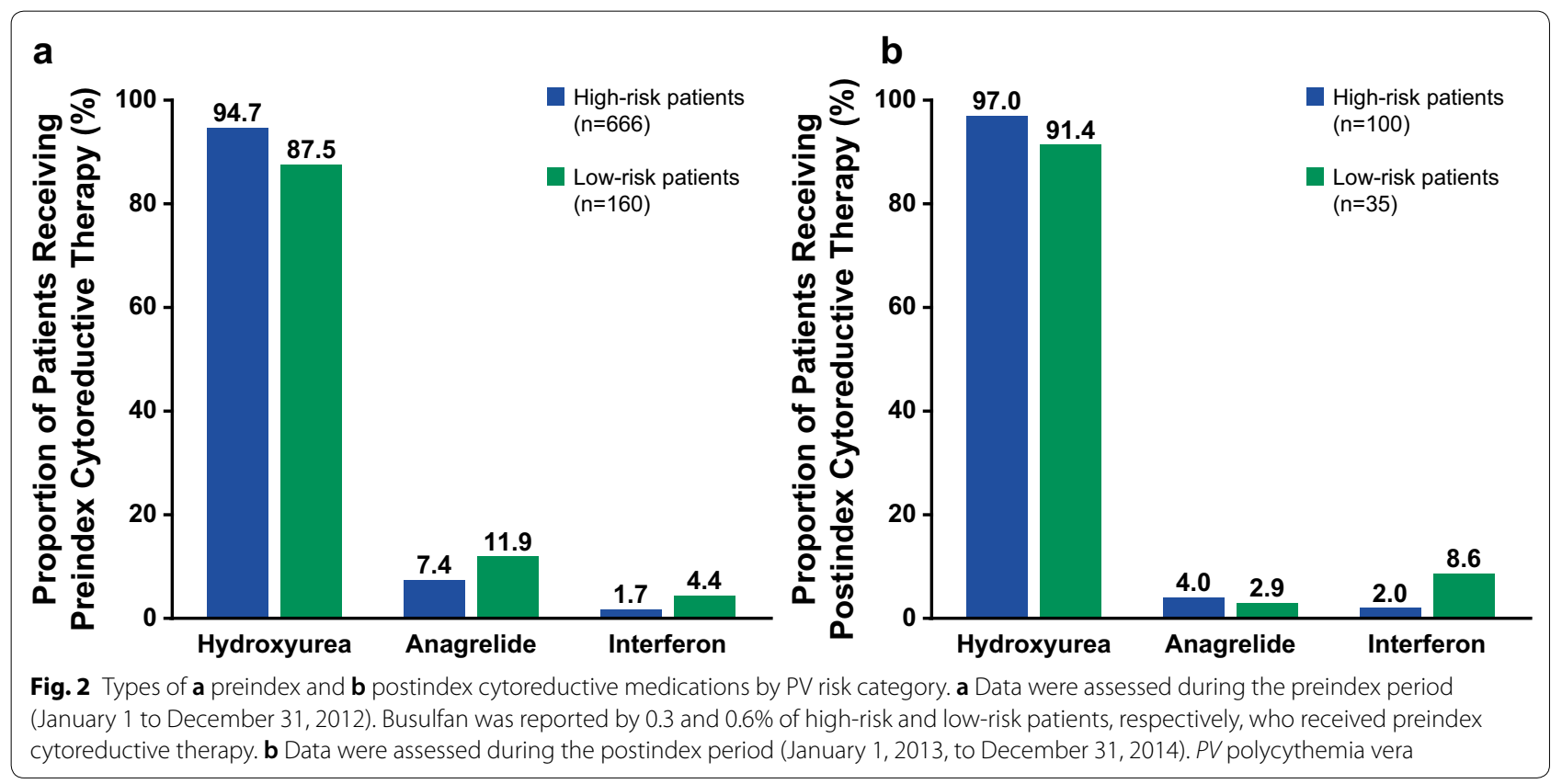

with high-risk PV should receive cytoreductive medication [6, 7], less than one-half of such patients (42.0\%) were treated with cytoreductive medication in the present analysis. Moreover, less than one-half of high-risk patients who were both $\geq 60$ years of age and had a history of TEs, and less than one-third of patients with a history of TEs who were $<60$ years of age received cytoreductive medication. The nature of this retrospective database analysis precluded clinical assessments of symptoms or specific outcomes. However, patients with high-risk PV were 


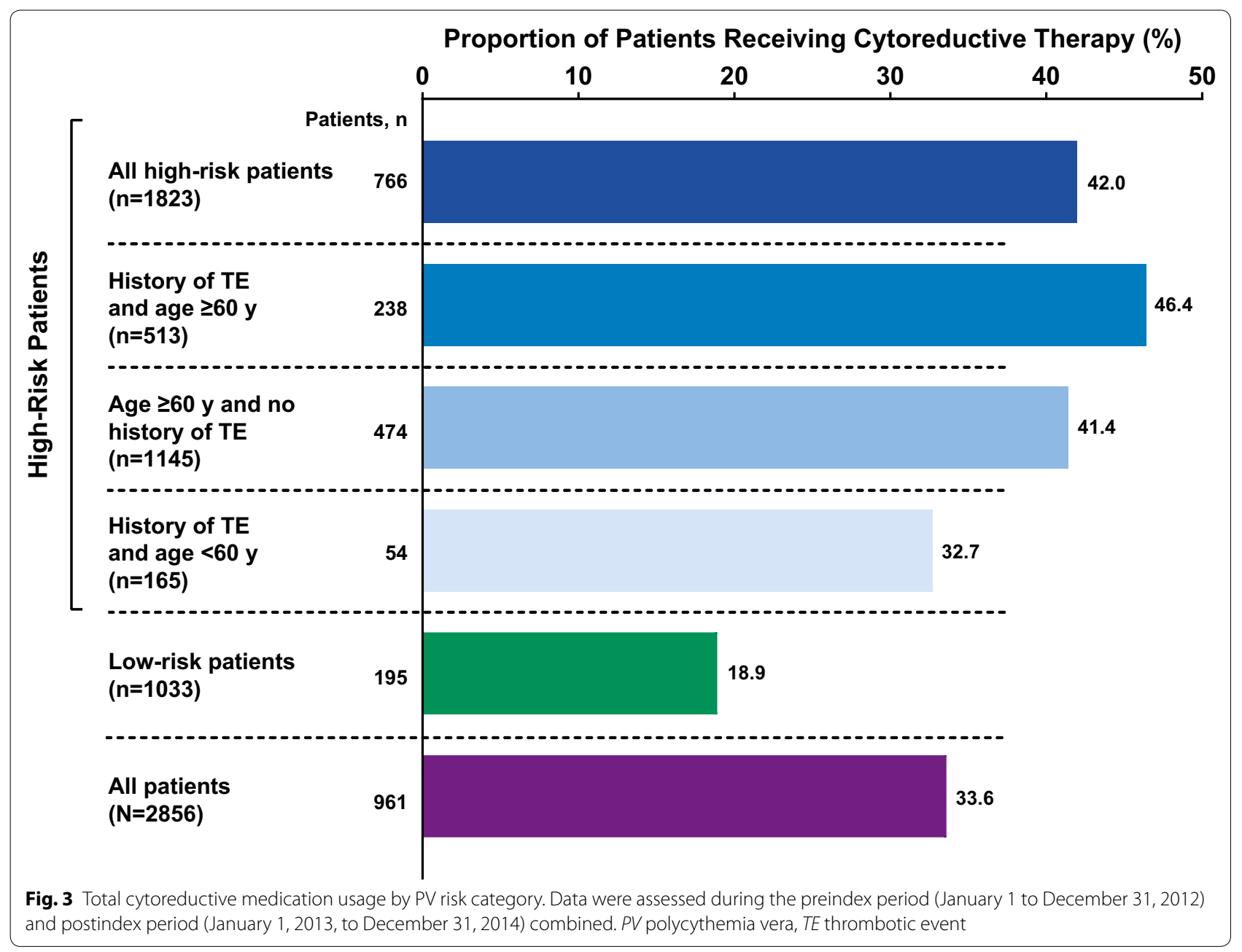

more likely to have cardiovascular comorbid conditions (hypertension, type 2 diabetes mellitus, and congestive heart failure) and were more likely to be prescribed cardiovascular medication. The age difference between the high- and low-risk groups may have contributed to the difference in cardiovascular comorbid condition rates.

An index date of January 1, 2013, was chosen in an effort to collect data from a time period when treating physicians could be reasonably expected to follow the ELN recommendations. However, it is important to note that in July 2017, NCCN Guidelines ${ }^{\circledR}$ were released pertaining to the treatment of patients with PV; these guidelines were updated in September 2017 [7]. The recommendations in the NCCN Guidelines ${ }^{\circledR}$ are quite consistent with the ELN's general recommendation that high-risk patients with PV be treated with hydroxyurea, interferons, or ruxolitinib, depending on their treatment history. Findings from this study suggest that prescribing physicians could benefit from increased awareness of consensus guidelines for the treatment of PV. Methods to improve physician education, such as increased availability of PV-focused continuing medical education materials and review articles targeting physicians, should be considered to improve guideline adherence and treatment outcomes in patients with PV.

The primary limitations associated with this study are inherent to all retrospective claims-based analyses. These include the assumption that claims were coded correctly and that patients were accurately identified as having PV (i.e., not secondary polycythemia). Furthermore, medication use was evaluated based solely on insurance claims data; the types of treating physicians who prescribed the drugs were not available in the Truven Health MarketScan database, and actual drug use during the study period was not confirmed. Finally, this study only included patients who were commercially insured or had supplemental Medicare insurance, and might not be generalizable to patients with other forms of coverage. 


\section{Conclusions}

This analysis of real-world treatment patterns indicates that most patients with high-risk PV do not receive cytoreductive medication, despite issued treatment guidelines. Given the increased mortality of patients with PV compared with age-matched subjects without PV [4], the present data suggest that a considerable proportion of patients with high-risk PV would likely benefit from revised treatment plans that align with current clinical guideline recommendations.

\begin{abstract}
Abbreviations
AML: acute myeloid leukemia; CDHP: consumer-driven health plan; ELN: European LeukemiaNet; EPO: exclusive provider organization; HDHP: high-deductible health plan; HMO: health maintenance organization; IV: intravenous; MF: myelofibrosis; MM: multiple myeloma; MPN: myeloproliferative neoplasm; NA: not applicable; NCCN: National Comprehensive Cancer Network; NSAID: nonsteroidal anti-inflammatory drug; POS: point of service; PPO: preferred provider organization; PV: polycythemia vera; TE: thrombotic event.
\end{abstract}

\section{Authors' contributions}

DP, PC, and SP participated in coordinating the study, reviewing and revising the manuscript, and approved the final manuscript for submission. KAE and MB participated in analyzing data and reviewing and revising the manuscript. All authors read and approved the final manuscript.

\section{Author details}

${ }^{1}$ Incyte Corporation, 1801 Augustine Cut-Off, Wilmington, DE 19803, USA.

${ }^{2}$ Truven Health Analytics, an IBM Company, 75 Binney St., Cambridge, MA 02142, USA.

\section{Acknowledgements}

Editorial assistance was provided by Jane Kovalevich, Ph.D. (Complete Healthcare Communications, LLC [West Chester, PA, a CHC Group company]), whose work was funded by Incyte Corporation.

\section{Competing interests}

DP, PC, and SP are employees and stockholders of Incyte Corporation. KAE and MB are employees of Truven Health Analytics, an IBM company, which received a research contract to conduct this study with and on behalf of Incyte Corporation.

\section{Availability of data and materials}

The data sets used and/or analyzed during the current study are available from the corresponding author on reasonable request.

\section{Consent for publication}

Not applicable.

Ethics approval and consent to participate

Not applicable.

\section{Funding}

Incyte Corporation.

\section{Publisher's Note}

Springer Nature remains neutral with regard to jurisdictional claims in published maps and institutional affiliations.

Received: 27 April 2018 Accepted: 28 June 2018

Published online: 09 July 2018

\section{References}

1. Agarwal M, Malhotra H, Chakrabarti P, Varma N, Mathews V, Bhattacharyya J, et al. Myeloproliferative neoplasms working group consensus recommendations for diagnosis and management of primary myelofibrosis, polycythemia vera, and essential thrombocythemia. Indian J Med Paediatr Oncol. 2015:36:3-16.

2. Arber DA, Orazi A, Hasserjian R, Thiele J, Borowitz MJ, Le Beau MM, et al. The 2016 revision to the World Health Organization classification of myeloid neoplasms and acute leukemia. Blood. 2016;127:2391-405.

3. Mesa R, Miller CB, Thyne M, Mangan J, Goldberger S, Fazal S, et al. Myeloproliferative neoplasms (MPNs) have a significant impact on patients' overall health and productivity: the MPN Landmark survey. BMC Cancer. 2016;16:167.

4. Price $G L$, Davis KL, Karve S, Pohl G, Walgren RA. Survival patterns in United States (US) Medicare enrollees with non-CML myeloproliferative neoplasms (MPN). PLoS ONE. 2014;9:e90299.

5. Marchioli R, Finazzi G, Landolfi R, Kutti J, Gisslinger H, Patrono C, et al. Vascular and neoplastic risk in a large cohort of patients with polycythemia vera. J Clin Oncol. 2005;23:2224-32.

6. Barbui T, Barosi G, Birgegard G, Cervantes F, Finazzi G, Griesshammer M, et al. Philadelphia-negative classical myeloproliferative neoplasms: critical concepts and management recommendations from European LeukemiaNet. J Clin Oncol. 2011;29:761-70.

7. National Comprehensive Cancer Network. NCCN clinical practice guidelines in oncology. Myeloproliferative neoplasms. Version 2.2018. https:// www.nccn.org/professionals/physician_gls/pdf/mpn.pdf. Accessed 14 Feb 2018

8. Tefferi A, Barbui T. Polycythemia vera and essential thrombocythemia: 2017 update on diagnosis, risk-stratification, and management. Am J Hematol. 2017:92:94-108.

\footnotetext{
Ready to submit your research? Choose BMC and benefit from:

- fast, convenient online submission

- thorough peer review by experienced researchers in your field

- rapid publication on acceptance

- support for research data, including large and complex data types

- gold Open Access which fosters wider collaboration and increased citations

- maximum visibility for your research: over 100M website views per year
}

At $B M C$, research is always in progress.

Learn more biomedcentral.com/submissions 